\title{
Circulating tumor cells as marker of poor prognosis in metastatic lung cancer: a pilot study
}

\author{
Mônica Taiane de Macêdo Diaz', Emne Ali Abdallah', Milena Shizue Tariki², Alexcia Camila Braun', \\ Aldo Lourenço Abbade Dettino², Ulisses Ribaldo Nicolau², Vanessa da Silva Alves ${ }^{1}$ \\ and Ludmilla Thomé Domingos Chinen ${ }^{1 *}$ (D)
}

\begin{abstract}
Background: Circulating tumor cells (CTCS) play an important role in progression and metastasis, particularly in form of cluster, which is called circulating tumor microemboli (CTM), and can be found in the peripheral blood of cancer patients. The aim of this study was to evaluate the presence of CTCS and CTM, and its influence on tumor progression in lung cancer patients.

Methods: CTCS were isolated by Isolation by Size of Epithelial Tumor cells (ISET $\left.{ }^{\oplus}\right)$ Technology. The samples of metastatic lung cancer patients were collected before the beginning of systemic chemotherapy. CTCs and CTM were identified according to their morphological features.

Results: Fifteen patients were analyzed. Patients who had CTM in blood previously the beginning of systemic therapy had poor progression-free survival (PFS) compared to those with absence of CTM, although without statistical significance (median PFS 3.1 months $\times 6.7$ months, $p=0.29$ ). Moreover, patients without any prior treatment had less than $3 \mathrm{CTCs} / \mathrm{mL}$ compared to patients previously exposed to chemotherapy, who had 3 $\mathrm{CTCs} / \mathrm{mL}$ or more $(p=0.31)$. Additionally, these patients, with prior treatment, showed poor PFS, compared to chemo-naive patients, although without statistical significance (mean PFS: 4.6 months $\times 7.3$ months, $p=0.47$ ).

Conclusions: We identified, even in a limited number of samples, that an elevated baseline levels of CTCs and the presence of CTM were associated with poor prognosis in patients with metastatic lung cancer. In addition, we showed that an increase of CTCS counts could indicate a pre-existing resistance. However, further studies with a large cohort are needed to support this information.
\end{abstract}

Keywords: Circulating tumor cells, Circulating tumor microemboli, Metastasis, Metastatic lung cancer

\section{Background}

Lung cancer is a public health issue, representing the most frequently diagnosed and with higher mortality rate in men and the second in women, being responsible for about 1.59 million deaths in the world [1]. This fact is due to several reasons, including increases in life expectancy, higher pregnancy age, poor nutrition, sedentary lifestyle and cigarette smoking [2].

\footnotetext{
* Correspondence: ludmilla.chinen@accamargo.org.br

${ }^{1}$ International Research Center, A.C. Camargo Cancer Center, Rua Taguá, 440, Liberdade, São Paulo, SP 01508-010, Brazil

Full list of author information is available at the end of the article
}

Metastases are the major cause of tumor progression and consequently death due to cancer [3]. Circulating tumor cells (CTCs) are rare cells coming from the primary tumor or metastatic site that can be detached and, therefore, invade blood circulation, and are known to play an important role in metastasis process [4]. These cells have specific intrinsic features of invasion and survival in blood circulation. CTCs can pass through a series of alterations, such as epithelial-mesenchymal transition (EMT), a well-known conformational change (phenotypic) that permit the invasion to blood vessels as well as overflow to distant sites [5]. CTC analysis has been shown to be a good marker for evaluation of tumor 
progression in numerous studies [6-8]. In addition, these cells are useful in monitoring treatment response, contributing for advances in personalized medicine [9].

Circulating tumor microemboli (CTM) are clusters of two or more CTCs that can play an important role in metastatic cascade. CTM may resist cell death in blood circulation, therefore, an inhospitable site, and can be responsible for reaching more focus of micro-metastasis when compared to isolated CTCs $[10,11]$. This aggressive feature of CTM is due to this phenotype, as this structure can be associated to leukocytes, fibroblasts, endothelial cells or platelets, which can add protection against external agents and another immune systemrelated cells into blood circulation [12].

The treatment of metastatic lung cancer patients is based mainly in tumor molecular characteristics, number and locality of metastasis as well as the overall health of patient [13]. Therefore, the treatment consists in surgery, chemotherapy, targeted therapy, immunotherapy, and radiation therapy [14]. After recurrence or progressive disease, the treatment is usually modified, starting a new line of treatment [15]. These data reinforce the need of new methodologies and tools to analyze disease progression along with imaging and to increase the accuracy of clinical follow-up.

With the emergence of new diagnostic technologies in the era of personalized medicine on cancer monitoring and treatment, the search for approachable markers becomes important. So, the analysis of CTCs and CTM may offers a minimally invasive form of monitoring treatment failure, tumor progression and recurrence [5]. Therefore, the aim of this study was to evaluate the prognostic factor of CTCs and CTM in metastatic lung cancer patients.

\section{Methods}

This is a retrospective study performed at International Research Center (CIPE) at A.C. Camargo Center. There were included patients older than 18 years, with nonsmall cell lung cancer, at the beginning of palliative treatment (baseline; metastasis diagnosis or progressive disease). Blood from 15 patients with metastatic lung cancer was analyzed. Informed consent was obtained from all participants included in the study, that was previously approved by our ethical committee (A.C. Camargo Cancer Center; reference number: 1367/10). For CTCs analysis, $8 \mathrm{~mL}$ of peripheral blood were collect in EDTA tubes. As negative control, blood from healthy donors was used and as positive control, blood from healthy donors spiked with A549 cell line (lung adenocarcinoma cell line) maintained in culture. The samples were collected before the beginning of a new systemic chemotherapy (baseline), in both chemotherapynaive patients or at protocol change by disease progression. Only patients with histological lung cancer confirmation were included and all patients underwent chest computed tomography for monitoring progression.

The ISET $^{\circ}$ (Isolation by Size of Epithelial Tumor cells; Rarecells Diagnostics, Paris, France) technology was used for CTCs isolation and enumeration. Blood samples were diluted (1:10) in an erythrocyte-lysis buffer (Rarecells Diagnostics) added to a $2 \%$ of formaldehyde at $\mathrm{pH}$ 7.35. Then, the solution was homogenized for 10 min until the filtration. The blood was pipetted on the block that is coupled to a polycarbonate membrane with 10 spots with calibrated $8 \mu \mathrm{m}$ pores. ISET works by negative pressure, therefore, cells smaller than $8 \mu \mathrm{m}$ (e.g.: lymphocyte and neutrophils), pass through the filter and are further discarded. Considering the fact that CTCs have the same size or larger than $12 \mu \mathrm{m}$ [16], both isolated CTCs and CTM get trapped on the membrane, for posterior analysis. Blood samples from healthy volunteers were collected as negative controls.

CTC characterization was performed in four spot by patient using immunocytochemistry method, with antiCD45 antibody (1:100; clone 2B11+ PD7/26, Dako ${ }^{\text {tw }}$, Carpinteria, California, USA), a surface leukocyte common antigen, according with previous works [17]. The slides were evaluated in a light microscopy and the identification of isolated and clusters of cells were made according its morphologic features (nuclear size equal or larger than $12 \mu \mathrm{m}$, irregularity of the nuclear contour, presence of a visible cytoplasm and high nuclear-tocytoplasmic ratio).

For statistical analysis, a description of each group was performed according to clinic pathological characteristics (sex, age, histological type, histological grade, TNM) and treatment. To evaluate differences between groups, the chi-square test was used for categorical variables. Progression-free survival (PFS) was obtained using the Kaplan-Meier method and the difference between curves was compared using the log-rank method. Statistical analysis was performed using SPSS software for Windows, version 15 . The values of $\mathrm{p}$ were considered significant when $\leq 0.05$.

\section{Results}

There were analyzed CTCs from 15 patients with metastatic lung cancer. All patients experienced disease progression, and 10 patients (66.7\%) progressed to death. The median PFS of all patients was 4.3 months (1.0 - 7.6 months).

All patients (100\%) included had stage IV lung cancer (accordingly to The American Joint Committee on Cancer - AJCC [18]). Among all metastatic patients, $86.7 \%$ presented involvement in one or more new metastatic site at the time of collection. The majority carried T3 and T4 tumors (66.7\%), and a half had lymph node 


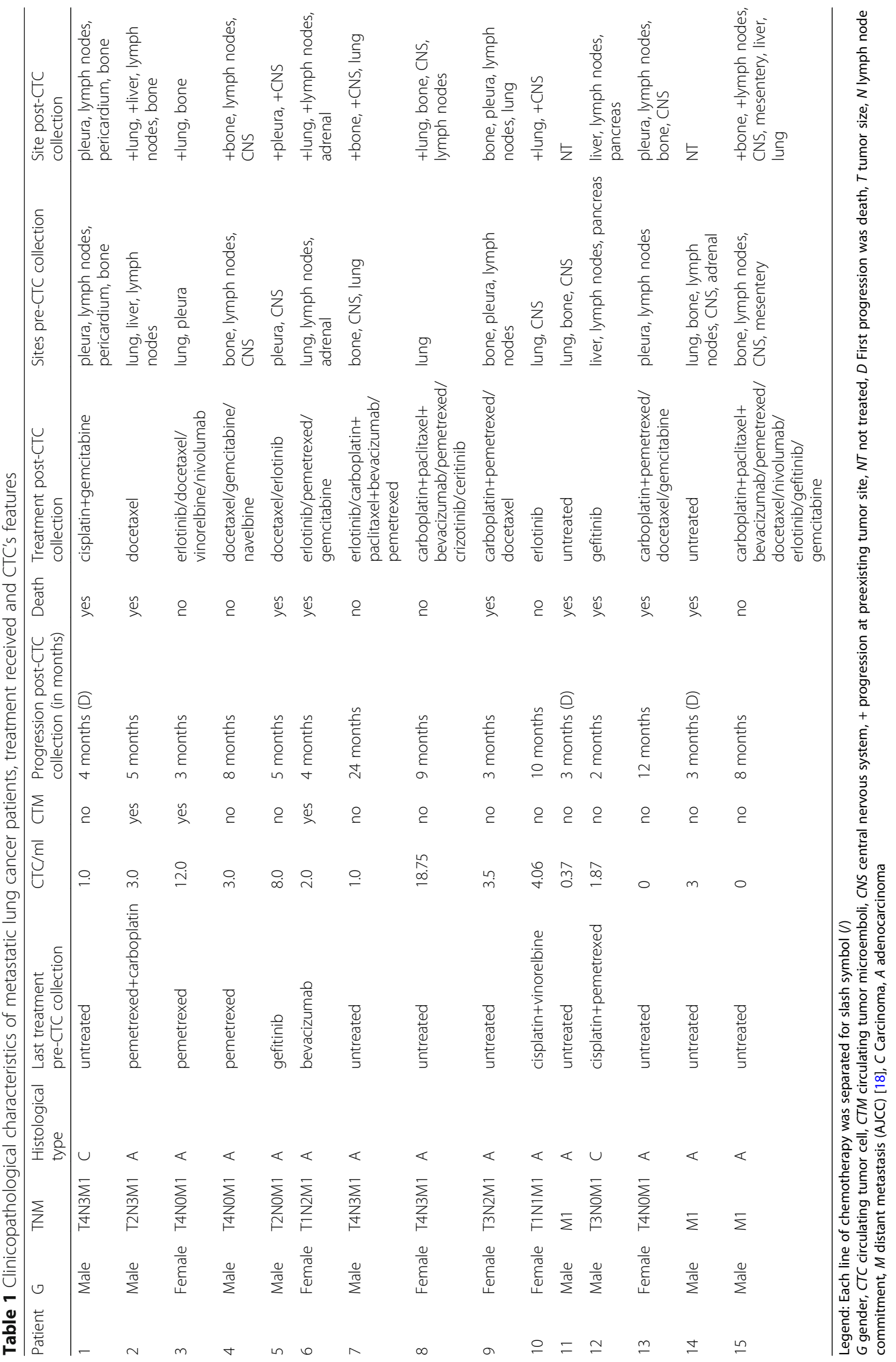


Table 2 Description and percentages of CTCs counts with and without pre-treatment

\begin{tabular}{|c|c|c|c|}
\hline \multirow{2}{*}{$\begin{array}{l}\text { Previous } \\
\text { treatment }\end{array}$} & \multicolumn{2}{|l|}{ CTC count } & \multirow[t]{2}{*}{$P$ value } \\
\hline & $<3 \mathrm{CTCs} / \mathrm{mL}$ & $\geq 3 \mathrm{CTCs} / \mathrm{mL}$ & \\
\hline No & $5(62.5 \%)$ & $3(37.5 \%)$ & 0.31 \\
\hline Yes & $2(28.6 \%)$ & $5(71.4 \%)$ & \\
\hline
\end{tabular}

commitment $(58.3 \%)$. The median age was 61 years-old $(48-79)$ at the time of blood collection. The predominant gender was male (60\%), 12 patients (80\%) were smokers or former smokers. The majority of tumors (80\%) were classified as adenocarcinoma histological type. These data can be observed in Table 1, according to individual characteristics patients.

\section{Circulating tumor cells (CTCs)}

The median number of CTCs detected per $\mathrm{mL}$ with ISET $^{\oplus}$ technology in these patients was $3.0 \mathrm{CTC} / \mathrm{mL}$ (0.0 - $18.8 \mathrm{CTCs} / \mathrm{mL})$.

We performed a comparison of CTCs counts between chemotherapy-naive patients and patients already underwent systemic treatment (one line or more) before CTC drawn (baseline). Using Fisher exact test, and CTC median as cut-off, we observed that patients that underwent chemotherapeutic treatment pre-baseline, showed more CTCs/mL compared with those chemotherapy-naive patients. We found that the majority of chemotherapy- naive patients $(5 / 8 ; 62.5 \%)$ had less CTCs than the median and that patients with previous treatment had more CTCs than the median $(5 / 7 ; 71.4 \%)(p=0.31$; Table 2). In addition, there were difference of time of progression between patients with and without previous treatment, where patients without prior treatment had better progression (mean PFS: 7.3 months; 95\% CI, 2.0 to 12.5) compared to those exposed previously to chemo agents (mean PFS: 4.6 months; 95\% CI, 2.5 to 6.7; $p=0.47$ ).

\section{Circulating tumor microemboli}

Among the 15 patients analyzed, three (20\%) presented CTM. After correlation with disease progression (DP) of each patient, characterized by imaging examination (RECIST criteria; version 1.1; Eisenhauer et al. 2009) [19], our results demonstrated that patients with CTM before the systemic treatment had poor prognostic, presented by worse median PFS (3.1 months $\times 6.7$ months, $p=0.29$ ) compared with those without CTM in the same moment, although with no statistical significance (Fig. 1). This information is shown in Table 1.

Patient 3 illustrate well our findings (Table 1). The patient is a 56 years-old woman, non-smoker, that was diagnosed on May 2010 with lung adenocarcinoma. She underwent thoracotomy and had three pulmonary nodules resected in the same date. She underwent two lines of chemotherapy before CTC collection (Carboplatin+Paclitaxel+Bevacizumab, then Pemetrexed), until tumor progression, the reason

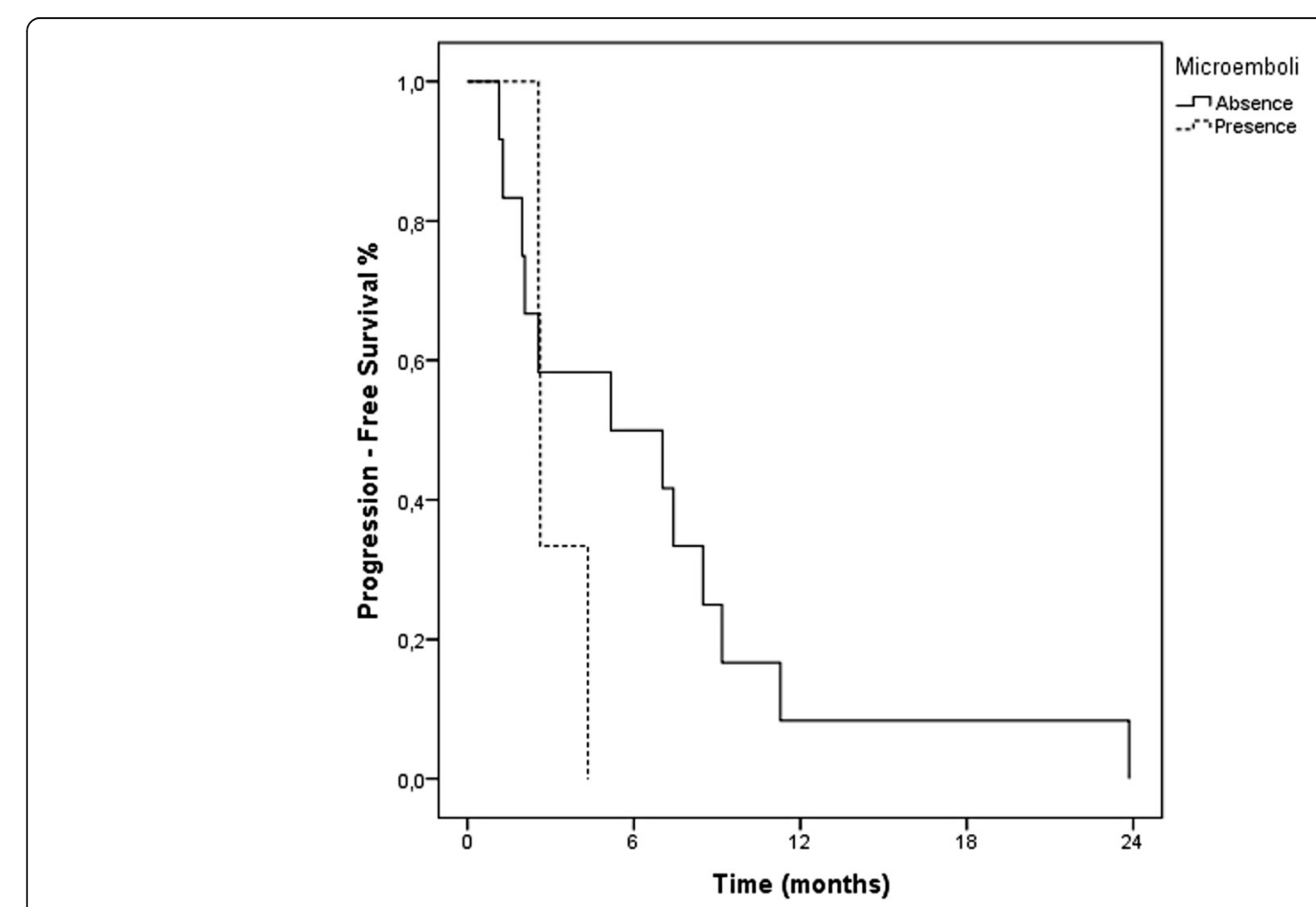

Fig. 1 Progression Free-Survival of patients with lung cancer that evaluated CTM before systemic treatment (With CTM, dotted line: median PFS of 3.1 months vs. Without CTM, continuous line: 6.7 months; $p=0.29$ ) 
why she was included in our study on July 2013. CTC analysis was performed when the patient presented progression based on the comparative computed tomography (CT) scan, when was evidenced an increase of the nodules in the lower lobe of the left lung on June 2013 compared with CT scan on March 2013 (21 e 19 mm vs. 26 e $19 \mathrm{~mm}$ ). CTCs count at this point was $12 \mathrm{CTC} / \mathrm{mL}$, in addition to the presence of CTM, highlighting the importance of CTC analysis to assess treatment effects. Furthermore, after this CTC count, a new progression was observed on September 2013, that can be observed in CT scans in Fig. 2.

\section{Discussion}

CTCs demonstrate a considerable advantage as liquid biopsy, compared to other circulating tumor markers, due the possibility to evaluate tumors whose mutations are unkown. In addition, CTC analysis allows the understanding of tumor biology, by molecular analysis and/or by expansion in culture for functional studies [20]. Our study supports its importance in the follow-up of metastatic lung cancer patients, demonstrating CTCs and CTM as markers of tumor progression, even in a small group of patients, enabling individual and personalized care.

CTC counting has been proven to be associated with some disease characteristics. Sonn et al. [21], described a study with 82 patients with lung cancer, where they found an association of CTC counts with stage disease, as patients with stage IV had more CTCs, compared to stages I-III of TNM system $(p=0,009)$. Therefore, one of our findings was the correlation of CTC counts with pretreatment status, where we observed that patients with pre-treatment had more CTCs per mL. Our results demonstrated a poor disease progression in patients previously treated compared to those without previous treatment, denoting that the previous line of treatment was not working and, probably, making possible the increase of viable and resistant CTCs in the blood circulation, paving the way for distant organ colonization. Therefore, the search for technologies that identify CTCs with maximum sensibility and specificity seems to be important, especially for monitoring treatment response, reflecting in less exposition to ineffective drugs.

The detection of CTM proved to be efficient in diverse studies, related to poor prognosis in some types of tumors by using other methodologies, that include ${ }^{\mathrm{HB}} \mathrm{CTC}-\mathrm{Chip}$ (herringbone CTC-chip), and HD-CTC (high-definitionCTC) assay [22, 23]. Present in small quantities in circulation, CTM represents around 2 to $5 \%$ of all CTCs [24]. Moreover, it is demonstrated that CTM capacity is up to 50 times in causing metastasis when compared to isolated CTCs, because their capacity to pass through capillary-sized vessels in vivo [24].

Many are the methodologies used on detection of CTCs and CTM [6]. However, ISET presents an advantage, as it identify more CTM compared to other methodologies, it isolates CTCs independently of expression of epithelial markers [16], phenotype that is demonstrated to be downregulated or even lost during metastatic cascade in many carcinomas, as a result of epithelial-to-mesenchymal transition [25]. In addition, ISET allows to perform a broad spectrum of techniques, such as immunocytochemistry, immunofluorescence, molecular analysis for pyrosequencing, FISH, Real-time PCR, among other [26-28]. Our study demonstrated ISET efficiency in detecting CTM and its correlation with a poor clinical outcome of patients with metastatic lung cancer. Hou et al. [29], using ISET, found a percentage of CTM (26\%) in small-cell lung cancer patients similar to our results (20\%). They demonstrated that even in less proportion in relation with isolated CTCs, these clusters were related with worse PFS, where patients with CTM had tumor progression in 4.6 months, in comparison to those without CTM that had tumor progression in 8.2 months $(p=0.001)$.

\section{Conclusions}

In conclusion, our study demonstrated ISET analytic capacity, even in samples stored frozen for up to 3 years,

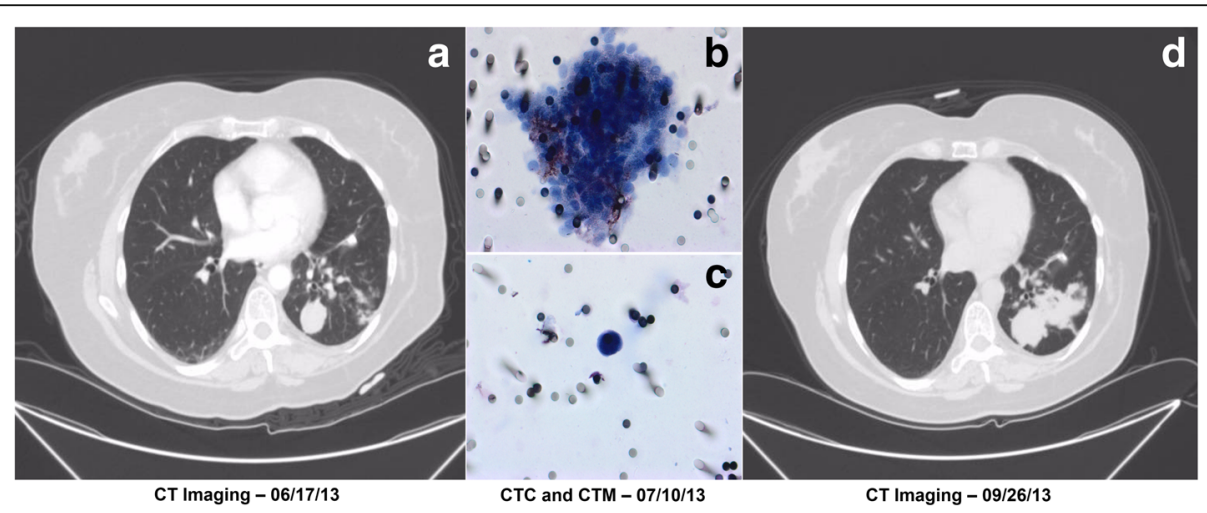

Fig. 2 Comparison of CT imaging before (a) and after (d) CTM (b) and CTC (c) detection 
identifying not only intact isolated CTCs, but also CTM. Moreover, our results demonstrated that CTM presence in blood circulation could be potentially related to poor prognosis in metastatic lung cancer patients, as patients that presented CTM, had tumor progression in a shorter time in comparison to those that did not present. These results complement CTC utility in clinical follow-up in these patients. However, it is a pilot study, and randomized clinical trials are necessary to show the prognostic value of these compartments of liquid biopsy in diagnosis and follow-up of metastatic non-small cell lung cancer patients, known for its high aggressiveness, treatment resistance, resulting in quick disease progression and high mortality rate.

\section{Abbreviations}

AJCC: The American Joint Committee on Cancer; CT: Computed tomography; CTCs: Circulating tumor cells; CTM: Circulating tumor microemboli; DP: Disease progression; EMT: Epithelial-mesenchymal transition; ISET: Isolation by Size of Epithelial Tumor cells; PFS: Progression free survival

\section{Acknowledgements}

Not applicable.

\section{Funding}

This work was supported by the São Paulo Research Foundation (FAPESP; grant number: 2012/01273-8) and National Council for Scientific and Technological Development (CNPq; grant number: 135530/2016-4).

\section{Availability of data and materials}

Please contact author for data requests.

\section{Authors' contributions}

MTMD performed the immunocytochemistry reaction, cytological examination and drafted the manuscript. EAA realized statistical analysis, contributed to cytological examination and helped to draft the manuscript. ACB and VSA contributed to sample collection and cytological reactions. MST, ALAD, URN participated in design of the study and clinical data collection. LTDC conceived the study, participated in the coordination of the study, cytological and statistics examination and helped to draft the manuscript. All authors read and approved the final manuscript.

\section{Ethics approval and consent to participate}

All procedures were performed according to the ethical standards of the institutional research committee (A.C. Camargo Cancer Center; reference number: 1367/10)

\section{Consent for publication}

Not applicable.

\section{Competing interests}

The authors declare that they have no competing interests.

\section{Publisher's Note}

Springer Nature remains neutral with regard to jurisdictional claims in published maps and institutional affiliations.

\section{Author details}

${ }^{1}$ International Research Center, A.C. Camargo Cancer Center, Rua Taguá, 440, Liberdade, São Paulo, SP 01508-010, Brazil. ²Department of Clinical Oncology, A.C. Camargo Cancer Center, Rua Prof. Antônio Prudente, 211, Liberdade, São Paulo, SP 01509-010, Brazil.
Received: 10 October 2017 Accepted: 5 February 2018

Published online: 12 March 2018

\section{References}

1. Ferlay J, Soerjomataram II, Dikshit R, Eser S, Mathers C, Rebelo M, Parkin DM, Forman DD, Bray F. Cancer incidence and mortality worldwide: sources, methods and major patterns in GLOBOCAN 2012. Int J Cancer. 2014;136:359-86.

2. Torre LA, Bray F, Siegel RL, Ferlay J, Lortet-tieulent J, Jemal A. Global cancer statistics, 2012. CA a cancer J Clin. 2015;65:87-108.

3. Nguyen DX, Bos PD, Massagué J. Metastasis: from dissemination to organ-specific colonization. Nat Rev Cancer. 2009;9:274-84.

4. Pantel K, Alix-Panabières C. Real-time liquid biopsy in cancer patients: fact or fiction? Cancer Res. 2013;73:6384-8

5. Bonnomet A, Brysse A, Tachsidis A, Waltham M, Thompson EW, Polette M, Gilles C. Epithelial-to-mesenchymal transitions and circulating tumor cells. J Mammary Gland Biol Neoplasia. 2010;15:261-73.

6. Alix-Panabieres C, Pantel K. Circulating tumor cells: liquid biopsy of cancer. Clin Chem. 2013;59:110-8.

7. Devriese LA, Voest EE, Beijnen JH, Schellens JHM. Circulating tumor cells as pharmacodynamic biomarker in early clinical oncological trials. Cancer Treat Rev. 2011:37:579-89.

8. Wu Z, Liu Z, Jiang H, Pan H. Circulating tumor cells predict survival benefit from chemotherapy in patients with lung cancer. Oncotarget. 2016;7:67586-96.

9. Plaks V, Koopman CD, Werb Z. Cancer. Circulating tumor cells. Science. 2013;341:1186-8.

10. Fidler IJ, Gersten DM, Riggs CW. Relationship of host immune status to tumor cell arrest, distribution, and survival in experimental metastasis. Cancer. 1977:40:46-55.

11. Chen JY, Tsai WS, Shao HJ, Wu JC, Lai M, Lu SH, Hung TF, Yang CT, Wu LC, Chen JS, Lee WH, Chang YC. Sensitive and specific biomimetic lipid coated microfluidics to isolate viable circulating tumor cells and microemboli for cancer detection. PLoS One. 2016;11:1-21.

12. Krebs MG, Metcalf RL, Carter L, Brady G, Blackhall FH, Dive C. Molecular analysis of circulating tumour cells-biology and biomarkers. Nat Rev Clin Oncol. 2014;11:129-44.

13. Collins LG, Haines C, Perkel R, Enck RE. Lung cancer: diagnosis and management. Am Fam Physician. 2007;75:56-63.

14. Spira A, Ettinger DS. Multidisciplinary management of lung cancer. N Engl J Med. 2004;350:379-92.

15. Dietrich MF, Gerber DE. Chemotherapy for advanced non-small cell lung cancer. Lung Cancer. 2016;170:119-49.

16. Krebs MG, Hou J-M, Sloane R, Lancashire L, Priest L, Nonaka D, Ward TH, Backen A, Clack G, Hughes A, Ranson M, Blackhall FH, Dive C. Analysis of circulating tumor cells in patients non-small cell lung cancer using epithelia marker-dependent and -independent approaches Matthew. J Thorac Oncol. 2012:7:306-15.

17. Chinen LTD, Lopes Mello CA, Abdallah EA, Ocea LMM, Buim ME, Breve NM, Gasparini JL, Fanelli MF, Paterlini-Bréchot P. Isolation, detection, and immunomorphological characterization of circulating tumor cells (CTCs) from patients with different types of sarcoma using isolation by size of tumor cells: a window on sarcoma-cell invasion. Onco Targets Ther. 2014;7:1609-17.

18. Amin MB, Edge S, Greene F, Byrd DR, Brookland RK, Washington MK, Gershenwald JE, Compton CC, Hess KR, Sullivan DC, Jessup JM, Brierley JD, Gaspar LE, Schilsky RL, Balch CM, Winchester DP, Asare EA, Madera M, Gress DM, Meyer L. AJCC cancer staging manual. 8rd ed. New York: Springer: 2017.

19. Eisenhauer EA, Therasse P, Bogaerts J, Schwartz LH, Sargent D, Ford R, Dancey J, Arbuck S, Gwyther S, Mooney M, Rubinstein L, Shankar L, Dodd L. New response evaluation criteria in solid tumours : revised RECIST guideline (version 1. 1). Eur J Cancer. 2009;45:228-47.

20. Tan CRC, Zhou L, El-Deiry WS. Circulating tumor cells versus circulating tumor DNA in colorectal cancer: pros and cons. Current Colorectal Cancer Reports. 2016;12:151-61.

21. Sonn C, Cho J, Kim J, Kang M, Lee J, Kim J. Detection of circulating tumor cells in patients with non-small cell lung cancer using a size-based platform. Oncol Lett. 2017;13:2717-22.

22. Aceto N, Bardia A, Miyamoto DT, Donaldson MC, Wittner BS, Spencer JA, Yu M, Pely A, Engstrom A, Zhu H, Brannigan BW, Kapur R, Stott SL, Shioda T, 
Ramaswamy S, Ting DT, Lin CP, Toner M, Haber DA. Circulating tumor cell clusters are Oligoclonal precursors of breast cancer metastasis. Cell. 2014;158:1110-22.

23. Carlsson A, Nair VS, Luttgen M, Keu KV, Horng G, Vasanawala M, Kolatkar A Jamali M, lagaru AH, Kuschner W, Loo BW Jr, Shrager JB, Bethel K, Hoh CK, Bazhenova L, Nieva J, Kuhn P, Gambhir SS. Circulating tumor microemboli diagnostics for patients with non-small cell lung cancer. J Thorac Oncol. 2015;9:1111-9.

24. Au SH, Storey BD, Moore JC, Tang Q, Chen Y, Javaid S, Sarioglu AF, Sullivan R, Madden MW, O'Keefe R, Haber DA, Maheswaran S, Langenau DM, Stott SL, Toner M. Clusters of circulating tumor cells traverse capillary-sized vessels. Proc Natl Acad Sci. 2016;113:4947-52.

25. Lecharpentier A, Vielh P, Perez-Moreno P, Planchard D, Soria JC, Farace F. Detection of circulating tumour cells with a hybrid (epithelial/mesenchymal) phenotype in patients with metastatic non-small cell lung cancer. Br J Cancer. 2011;105:1338-41.

26. Li H, Song P, Zou B, Liu M, Cui K, Zhou P, Li S, Zhang B. Circulating tumor cell analyses in patients with esophageal squamous cell carcinoma using epithelial marker-dependent and -independent approaches. Medicine (Baltimore). 2015;94:1-9.

27. Buim ME, Fanelli MF, Souza VS, Romero J, Abdallah EA, Celso ALM, Alves V Ocea LM, Mingues NB, Barbosa PN, Tyng CJ, Chojniak R, Chinen LTD. Detection of KRAS mutations in circulating tumor cells from patients with metastatic colorectal cancer. Cancer Biol Ther. 2015;16:1289-95.

28. Ma Y, Wang L, Yu F. Recent advances and prospects in the isolation by size of epithelial tumor cells (ISET) methodology. Technol Cancer Res Treat. 2013;12:295-309.

29. Hou JM, Krebs MG, Lancashire L, Sloane R, Backen A, Swain RK, Priest LJC, Greystoke A, Zhou C, Morris K, Ward T, Blackhall FH, Dive C. Clinical significance and molecular characteristics of circulating tumor cells and circulating tumor microemboli in patients with small-cell lung cancer. J Clin Oncol. 2012;30:525-32.

\section{Submit your next manuscript to BioMed Central and we will help you at every step:}

- We accept pre-submission inquiries

- Our selector tool helps you to find the most relevant journal

- We provide round the clock customer support

- Convenient online submission

- Thorough peer review

- Inclusion in PubMed and all major indexing services

- Maximum visibility for your research

Submit your manuscript at www.biomedcentral.com/submit

) Biomed Central 